\title{
Evaluation of Spatial and Temporal Distribution Changes of LST Using Landsat Images (Case Study:Tehran)
}

\author{
H. Kachar ${ }^{a *}$, A. R. Vafsian ${ }^{\text {b }}$, M. Modiri ${ }^{\text {c }}$, H. Enayati ${ }^{\text {a }}$, A. R. Safdari Nezhad a \\ ${ }^{a}$ K.N. Toosi university of Technology, Faculty of Geodesy and Geomatics Eng, Mirdamad Cross, Tehran, Iran - (hamedkachar, \\ Enayati_hamid, Safdari.Nezhad )@yahoo.com \\ b Tabriz University, Civil Engineering Faculty, Tabriz, Iran - a.vafsian@gmail.com \\ ${ }^{\mathrm{c}}$ Malek Ashtar University of Technology, Dept. of Geomatic Engineering, Lavizan Street, Tehran, Iran - mmodiri@ut.ac.ir
}

KEY WORDS: Remote sensing, Landsat Images, land surface temperature, urban heat islands, Tehran

\begin{abstract}
:
In traditional approach, the land surface temperature (LST) is estimated by the permanent or portable ground-based weather stations. Due to the lack of adequate distribution of weather stations, a uniform LST could not be achieved. Todays, With the development of remote sensing from space, satellite data offer the only possibility for measuring LST over the entire globe with sufficiently high temporal resolution and with complete spatially averaged rather than point values. the remote sensing imageries with relatively high spatial and temporal resolution are used as suitable tools to uniformly LST estimation. Time series, generated by remote sensed LST, provide a rich spatial-temporal infrastructure for heat island's analysis. in this paper, a time series was generated by Landsat8 and Landsat7 satellite images to analysis the changes in the spatial and temporal distribution of the Tehran's LST. In this process, The Normalized Difference Vegetation Index (NDVI) threshold method was applied to extract the LST; then the changes in spatial and temporal distribution of LST over the period 1999 to 2014 were evaluated by the statistical analysis. Finally, the achieved results show the very low temperature regions and the middle temperature regions were reduced by the rate of $0.54 \%$ and $5.67 \%$ respectively. On the other hand, the high temperature and the very high temperature regions were increased by $3.68 \%$ and $0.38 \%$ respectively. These results indicate an incremental procedure on the distribution of the hot regions in Tehran in this period. To quantitatively compare urban heat islands (UHI), an index called Urban Heat Island Ratio Index(URI) was calculated. It can reveal the intensity of the UHI within the urban area. The calculation of the index was based on the ratio of UHI area to urban area. The greater the index, the more intense the UHI was. Eventually, Considering URI between 1999 and 2014, an increasing about 0.03 was shown. The reasons responsible for the changes in spatio-temporal characteristics of the LST were the sharp increase in impervious surfaces, increased use of fossil fuels and greening policies.
\end{abstract}

\section{INTRODUCTION}

Nowadays, temperatures of the Metropolitan centers are increased due to several reasons (e.g. vegetation suppression, industrial life, population growth and etc) (Rose and Devadas, 2009). In General, urban heat islands (UHI), as an important indicator of the urban development, are defined as the urban regions which have the rather high temperature with respect to the surrounding (Chen et al, 2009). One of the main tools of the heat island's analysis is the estimation of the land surface temperature (LST) (Xu et al, 2009). The LST is one of the most important parameters in the physical processes of surface energy and water balance at local through global scales (Amiri et al, 2009). Knowledge of the LST provides information on the temporal and spatial variations of the surface equilibrium state and is of fundamental importance in many applications. As such, the LST is widely used in a variety of fields including evapotranspiration, climate change, hydrological cycle, vegetation monitoring, urban climate, environmental studies and etc. In urban areas, it helps to learn the local climate and the development of a city (Dai et al, 2010). The total area of districts with higher temperature changes year by year as the city develops. It is therefore significant to analyze the temporal and regional changes of land surface temperature in urban areas. In order to analyze and Evaluation of Spatial and Temporal Distribution Changes of LST ,there are two major approaches: (a) a method based on field observations of meteorological stations and (b) method based on the use of remote sensing technology (Malekpour et al, 2010).

Due to the lack of adequate distribution of weather stations, a uniform LST could not be achieved. Todays, With the development of remote sensing from space, satellite data offer the only possibility for measuring LST over the entire globe with sufficiently high temporal resolution and with complete spatially averaged rather than point values. the remote sensing imageries with relatively high spatial and temporal resolution are used as suitable tools to uniformly LST estimation (Li, 2006).

Study of urban heat islands by remote sensing done the first time by using NOAA satellite data (Balling and Brazell, 1988).

\footnotetext{
* Corresponding author
} 
Spatial resolution of NOAA satellite proper for providing small scale urban temperature maps. Then the thermal infrared data of Landsat satellite series with spatial resolution of 120 and 60 meters was applied to the surface temperature extraction(Weng, 2001). Xiao and Moddy (2005), investigated the relationship between land-use and land cover changes using Landsat TM and ETM images. Evaluation of urban development effects on the heat islands of the city of Guangzou in China by Weng and Yang (2004), using Landsat images showed that the expansion of construction and urban heat islands enhances the effect of heat islands. In the case of the heat island phenomenon, Pongracz et al. (2006), examined this phenomenon in different areas in the 10 densely populated city of Hungarian by MODIS images. The results of this study showed that with the increase of the population, the temperature difference city with the suburbs (UHI) has also increased. Gaffin et al. (2008), studied the heat island phenomenon and provided the required data from the weather stations inside and around the city. The results represent the temperature increase during the 12-year interval. Percentage of increase of temperature-related to changes of the regional and global climate and other percentage of the increase of the temperature of the city center are related to UHI. Numerous studies and research in related the Urban heat island has been performed (Malekpour et al, 2010). The results of this researches show that the effect of heat island has been more pronounced and consistent with the growth and development of the metropolis of Tehran. Heat island phenomenon can be studied from different aspects that the Earth's surface temperature changes caused by the existence of this phenomenon is one of the most important, therefore, the main objective of the present study is to investigate and evaluate of Spatial and Temporal Distribution Changes of land surface temprature in the metropolis of Tehran using Landsat satellite images.

\section{MATERIALS AND METHODS}

\subsection{Case Study Area}

Tehran, the capital of the Islamic Republic of Iran, modern urban, developing and growing urbanization and dating back tens of years, has a high population density and large area compared to the other cities. Tehran city geographically at 51 degrees and 17 minutes to 51 degrees and 33 minutes East and 35 degrees and 36 minutes to 35 degrees and 46 minutes north. This city is located in the South of the Alborz Mountains and the northern edge of the Central deserts of Iran in the relatively smoothly plain. It has an area of about 706 square kilometers and its average elevation is $1600 \mathrm{~m}$ above sea level. Figure (1), shows position of the study area.

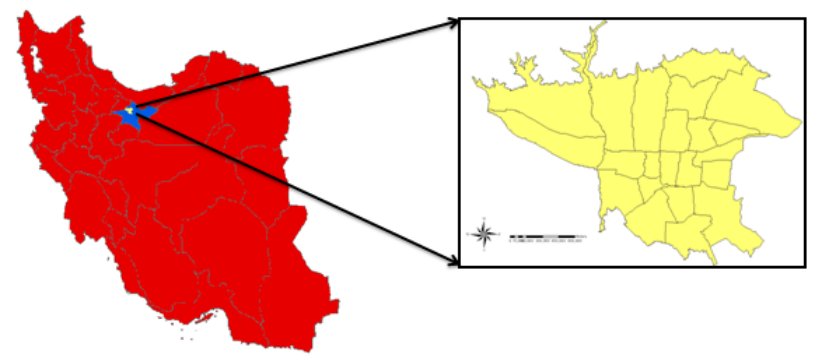

Figure 1. Location of case study area (22 zones of Tehran)

\subsection{Data}

In the present study were used two satellite image corresponds to sensors of the Landsat7 (ETM) and Landsat8 (OLI_TIRS) which features of satellite images were described in table (1). It should be noted that the aforementioned satellite images were downloaded from the site http://earthexplorer.usgs.gov.

\begin{tabular}{cccccc}
\hline Sensor & Date & $\begin{array}{c}\text { Time of } \\
\text { Imaging }\end{array}$ & $\begin{array}{c}\text { Number } \\
\text { of bands }\end{array}$ & Pass & Row \\
\hline ETM+ & 01-Aug-1999 & $7: 01$ & 8 & 164 & 35 \\
\hline $\begin{array}{c}\text { OLI- } \\
\text { TIRS }\end{array}$ & 02-Aug-2014 & $7: 08$ & 11 & 164 & 35 \\
\hline
\end{tabular}

Table 1. characteristics of satellite images used in the analysis

\subsection{LST retrieval from ETM data}

ETM 6-2 band was used to retrieval the land surface temperature. this band is very suitable for the detection of the temperature difference of the urban environment. In the following present the steps of retrieval the land surface temperature of ETM sensor. To extract the land surface temperature, the following three steps will be performed:

a) convert digital number of the band6 to spectral radiance with using equation (1) (Landsat Data User Hanbook, 2006):

$\mathrm{L}_{\lambda}=\left(\frac{\operatorname{LMAX}_{\lambda}-\mathrm{LMIN}_{\lambda}}{\mathrm{Q}_{\mathrm{calmax}}-\mathrm{Q}_{\mathrm{calmin}}}\right)\left(\mathrm{Q}_{\mathrm{cal}}-\mathrm{Q}_{\text {calmin }}\right)+\mathrm{LMIN}_{\lambda}$

\section{where}

$\mathrm{L}_{\lambda}=$ Spectral radiance at the sensor's aperture [W/(m2 sr $\left.\left.\mu \mathrm{m}\right)\right]$

$\mathrm{Q}_{\mathrm{cal}}=$ Quantized calibrated pixel value $[\mathrm{DN}]$

$\mathrm{Q}_{\text {calmin }}=$ Minimum quantized calibrated pixel value corresponding to $\mathrm{LMIN}_{\lambda}[\mathrm{DN}]$

$\mathrm{Q}_{\text {calmax }}=$ Maximum quantized calibrated pixel value corresponding to $\operatorname{LMAX}_{\lambda}[\mathrm{DN}]$

$\mathrm{LMIN}_{\lambda}=$ Spectral at-sensor radiance that is scaled to $\mathrm{Q}_{\mathrm{calmin}}$ $[\mathrm{W} /(\mathrm{m} 2 \mathrm{sr} \mu \mathrm{m})]$

$\operatorname{LMAX}_{\lambda}=$ Spectral at-sensor radiance that is scaled to $\mathrm{Q}_{\text {calmax }}$

$[\mathrm{W} /(\mathrm{m} 2 \mathrm{sr} \mu \mathrm{m})]$

b) Convert spectral radiance to the Brightness temperatures(BT) based on kelvin with using equation (2):

$$
\mathrm{BT}=\frac{\mathrm{K}_{2}}{\left\{\ln \left[\frac{\mathrm{K}_{1}}{\mathrm{~L}}+1\right]\right\}}
$$

Where

BT= Effective at-sensor brightness temperature $[\mathrm{K}]$

$\mathrm{K} 2=$ Calibration constant $2[\mathrm{~K}]$ is equivalent to the (1282.71)

$\mathrm{K} 1=$ Calibration constant $1[\mathrm{~W} /(\mathrm{m} 2 \mathrm{sr} \mu \mathrm{m})]$ is equivalent to the (666.09)

$\mathrm{L}=$ Spectral radiance at the sensor's aperture $[\mathrm{W} /(\mathrm{m} 2 \mathrm{sr} \mu \mathrm{m})]$ Ln = Natural logarithm

c) In the third stage, the emissivity and the temperature of the Earth's surface were calculated with using the method based on NDVI. 
One of the effective methods to estimate the temperature of the land surface is using of the hybrid model of the percentage of land cover, with the assumption that the soil and vegetation have a known emissivity, so with using the NDVI index, it can be calculated the amount of the compound and the incorporation of soil, vegetation and ... And with using this combination, it can be Obtained the emissivity and the temperature of the land surface (Sobrino et al., 2001). Therefore, one of the operational and functional ways to get emissivity, using the NDVI threshold method, which is based on it emissivity is divided to three level based on NDVI values.

1. NDVI $<0.2$ : In this case the pixels corresponding to soil dry and the mean value of emissivity is estimated to be $0.978\left(\varepsilon_{\mathrm{s}}=0.978\right)$

2. NDVI $>0.5$ : That represents the domain with abundant vegetation and the mean value of emissivity is estimated to be $0.985\left(\varepsilon_{\mathrm{V}}=0.985\right)$.

3. $0.2 \leq \mathrm{NDVI} \leq 0.5$ : In which case the pixels of a combination of soil and vegetation and the emissivity in this case can be calculated on the basis of the equation (3):

$$
\varepsilon=\varepsilon_{\mathrm{V}}+\varepsilon_{\mathrm{S}}\left(1-\mathrm{p}_{\mathrm{V}}\right)+\mathrm{d} \varepsilon
$$

Where, $\varepsilon$ is the Land surface emissivity, $\varepsilon_{\mathrm{v}}$ is the emissivity of full vegetation cover area, while $\varepsilon_{\mathrm{S}}$ is emissivity of bare soil and $\mathrm{Pv}$ is the vegetation fraction, which was determined by (4) (Sobrino et al., 2004):

$$
\mathrm{P}_{\mathrm{v}}=\left[\frac{\mathrm{NDVI}-\mathrm{NDVI}_{\min }}{\mathrm{NDVI}_{\max }-\mathrm{NDVI}_{\min }}\right]^{2}
$$

In which, NDVI $I_{\text {min }}$ is the NDVI value of bare soil $\left(\mathrm{NDVI}_{\min }=0.2\right)$. NDVImax is the NDVI value of full vegetation cover area ( NDV Imax $=0.5$ ).

In respect of (3), $d \varepsilon$ the effect of geometric distribution of natural surfaces, which is an approximate basis using the equation (5):

$$
\mathrm{d} \varepsilon=\left(1-\varepsilon_{\mathrm{S}}\right)\left(1-\mathrm{P}_{\mathrm{v}}\right) F \varepsilon_{\mathrm{v}}
$$

Where F is the shape factor, (Sobrino et al., 1990) that the mean value with the assumption of different geometric distribution of levels, is equal 0.55 .

Getting the values of the emissivity, land surface temperature (LST) through the equation (6) calculated based on Kelvin (Artis and Carnahan, 1982):

$$
\mathrm{LST}=\frac{\mathrm{BT}}{1+\left[\left(\frac{\lambda \times \mathrm{BT}}{\rho}\right) \times \ln \varepsilon\right]}
$$

Where $\lambda$ is the emitted radiance wavelength, $\rho=1.438 \times 10^{-2}$ and $\varepsilon$ is emissivity.

In the final stage, the equation (7) was used to convert kelvin to centigrade.

$$
\text { C }=\text { Kelvin }-273.15
$$

\subsection{LST retrieval from (OLI-TIRS) data}

To retrieval the temperature of the Earth's surface, was used the band10 of OLI_TIRS sensor. To extract the LST, such as section (2.3), three steps take place:

a) convert digital number of the band 10 to spectral radiance with using equation (8):

$$
\mathrm{L}_{\lambda}=\left(\text { Gain } \times \mathrm{Q}_{\mathrm{cal}}\right)+\text { Bias }
$$

Where $\mathrm{Q}_{\mathrm{cal}}$ is the digital number of every pixel, Gain is equal to 0.0003342 and bias is 0.1 , this information can be obtained from the header file of the images.

b) Convert spectral radiance to the Brightness temperatures(BT) based on kelvin with using equation (2).

Where

BT $=$ Effective at-sensor brightness temperature $[\mathrm{K}]$

$\mathrm{K} 2=$ Calibration constant 2 of the band $10[\mathrm{~K}]$ is equivalent to the (1321.08)

$\mathrm{K} 1=$ Calibration constant 1 of the band $10[\mathrm{~W} /(\mathrm{m} 2$ sr $\mu \mathrm{m})]$ is equivalent to the (774.89)

$\mathrm{L}=$ Spectral radiance at the sensor's aperture $[\mathrm{W} /(\mathrm{m} 2 \mathrm{sr} \mu \mathrm{m})]$

c) In the third stage, the emissivity and the LST were calculated such as section (2.3).

\subsection{Evaluation of Spatial and Temporal Distribution of LST}

To study and Evaluation of Spatial and Temporal Distribution changes of LST in the metropolis of Tehran, we divided the LST into 5 categories using Mean-Standard deviation Method (Xu et al., 2011)(Table2).

\begin{tabular}{cc}
\hline Category & Ranges \\
\hline very low temperature (class1) & LST $<\mu-2$ std \\
low temperature (class2) & $\mu-2$ std $\leq$ LST $<\mu-1$ std \\
middle temperature (class3) & $\mu-1$ std $\leq$ LST $\leq \mu+1$ std \\
high temperature(class4) & $\mu+1$ std $<$ LST $\leq \mu+2$ std \\
very high temperature(class5) & LST $>\mu+2$ std
\end{tabular}

Table 2. Usage of mean-standard deviation method to devided land surface temperature

In the table 2, LST represent the land surface temperature, $\mu$ and std, respectively represent the average and standard deviation of surface temperature of any images.

To quantitatively compare urban heat islands (UHI), in Tehran metropolis, between the years 1999 to 2014, an index called Urban Heat Island Ratio Index (URI) was calculated (equation (9)) (Xu and Chen, 2004). It can reveal the intensity of the UHI within the urban area. The calculation of the index was based on the ratio of UHI area to urban area.

$\mathrm{URI}=\frac{1}{100 \mathrm{~m}} \sum_{\mathrm{i}=1}^{\mathrm{n}} \mathrm{w}_{\mathrm{i}} \mathrm{p}_{\mathrm{i}}$

In which, $\mathrm{m}$ is the number of temperature Classes, $\mathrm{n}$ is the number of temperaturer classes higher than the mean temperature. $\mathrm{w}_{\mathrm{i}}$ is the amount of weight of temperature classes higher than the mean temperature that means the amount of weight the of classes 4 and 5 , which the amount of weight can be considered respectively as 4 and $5 . P_{i}$ is the Percent of 
occupied area by the temperature classes of higher than mean temperature.

\section{RESULTS AND DISCUSSION}

Using the equations expressed in sections (2.3) and (2.4), the maps of LST of Tehran were produced during the 1999 and 2014 (Figure 2 \& 3).

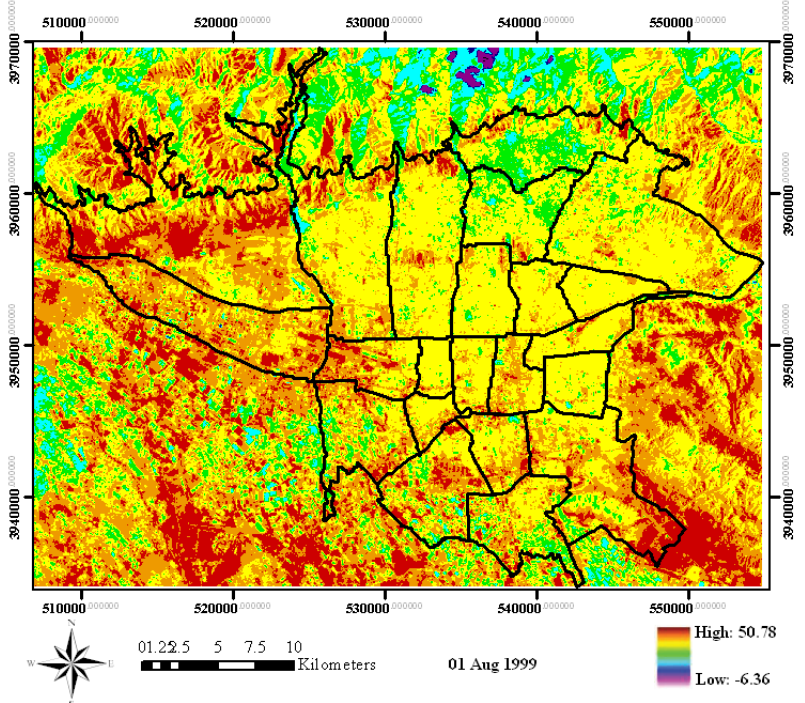

Figure 2. The map of LST of the Tehran metropolis (1 August 1999)

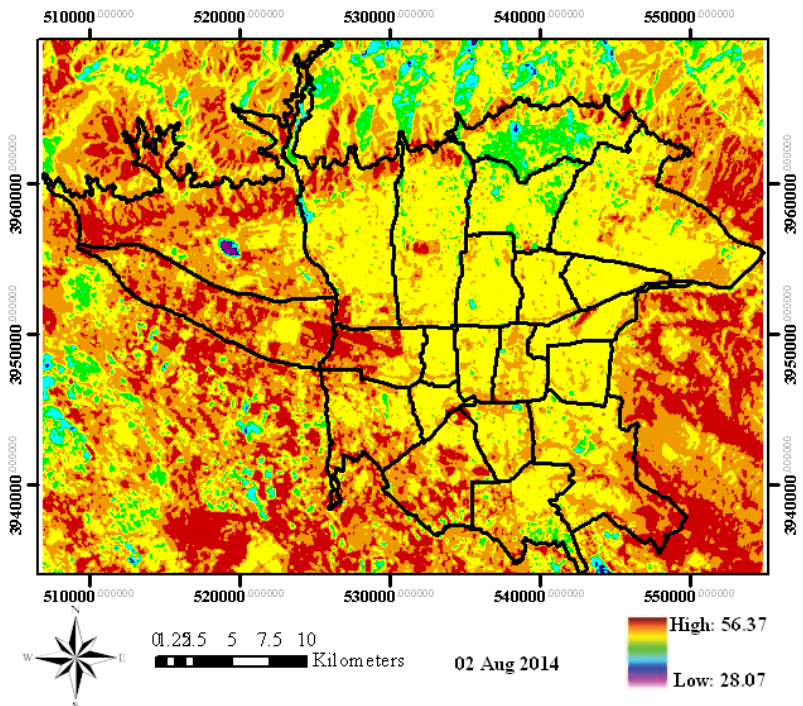

Figure 3. The map of LST of the Tehran metropolis (02 August 2014)

In order to Evaluation of Spatial and Temporal Distribution Changes of LST of Tehran metropolis, based on statistical parameters of mean and standard deviation related to any of the images, based on the table 2, the temperature of the Earth's surface was divided into 5 categories and finally the maps of LST of the Tehran metropolitan were produced (Figures 4 and $5)$.

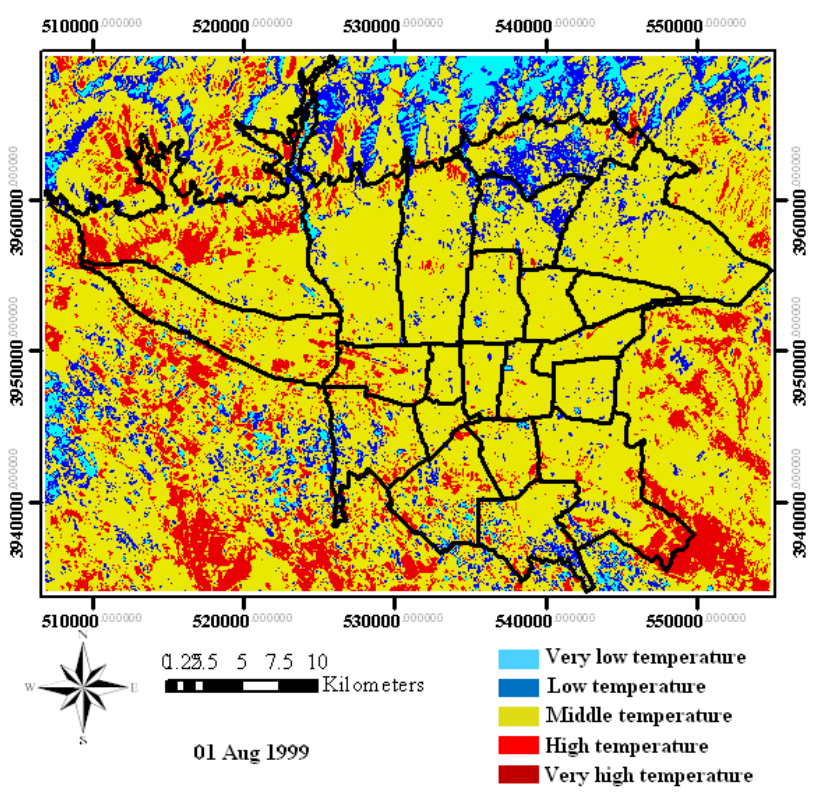

Figure 4. The map of Spatial Distribution Changes LST of the Tehran metropolis (1 August 1999)

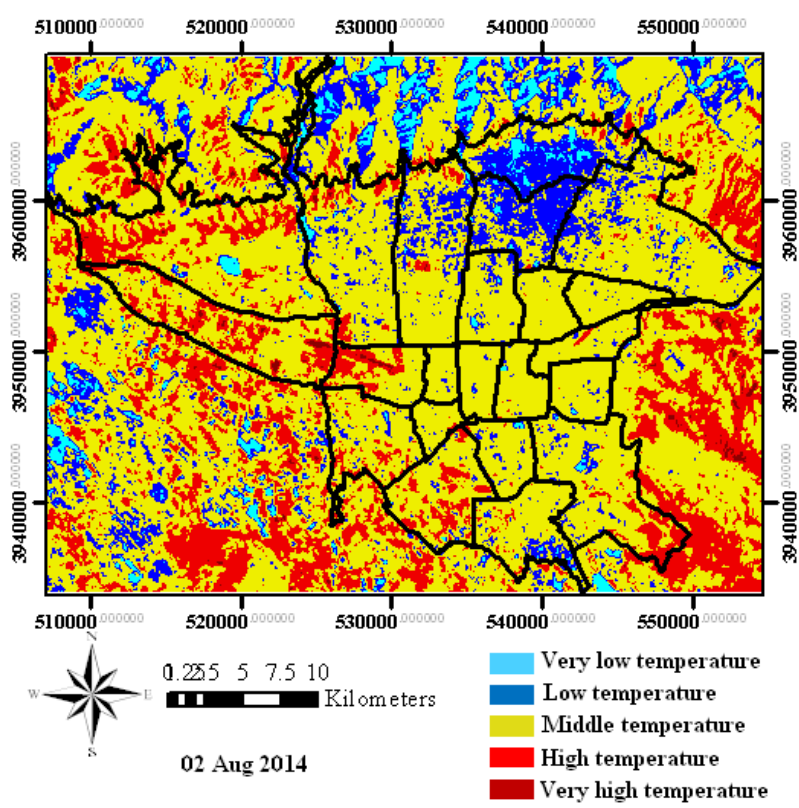

Figure 5. The map of Spatial Distribution Changes LST of the Tehran metropolis (02 August 2014)

According to figures 4 and 5, the temperature classes of low and very low which respectively represents regions of relatively cool and cool, in the North and mountainous ranges and the South and South West of the most spread over. In the mountainous sections of the North, due to the existence of the River, the Valley, vegetation and relatively mild weather, this topic is justified. In the the range of South and southwest due to the existence of continuous agricultural lands, gardens and vegetation, were developed the scope of the temperature classes with low temperature and very low. In addition to the almost 
continuous spectrum is a relatively cool and cool zones in the northern and southern regions, such as in the figure of the aforementioned, spots were scattered in other parts of the study area which representing the geographical position as such as parks and urban green spaces.

the middle temperature regions, covered the extent area of the study area and particularly is centralized in city center.

By Visual comparison of figures 4 and 5, obviously can be understand that some changes take place within a relatively cool, cool and middle regions during the passing of time, especially in the northern and Western zones, that seems to be the main cause of this type of transformation, changes of land use/land cover. The class of high temperature is expanded, in the West and South-west regions and East and South-East regions. By comparing the figures 4 and 5, is clearly evident the development of the high temperature class and create very high temperature class in the range to the West, South West, East and South East.

Table 3, shows the percentage of the area of each of the classes of surface temperature in Tehran metropolis.

\begin{tabular}{cccccc}
\hline Time & $\begin{array}{c}\text { Very low } \\
\text { temperature }\end{array}$ & $\begin{array}{c}\text { Low } \\
\text { temperature }\end{array}$ & $\begin{array}{c}\text { Middle } \\
\text { temperature }\end{array}$ & $\begin{array}{c}\text { High } \\
\text { temperature }\end{array}$ & $\begin{array}{c}\text { Very high } \\
\text { temperature }\end{array}$ \\
\hline $\begin{array}{c}01 \\
\text { Aug }\end{array}$ & $3.56 \%$ & $10.58 \%$ & $71.94 \%$ & $13.92 \%$ & $0 \%$ \\
1999 & & & & & \\
\hline $\begin{array}{c}02 \\
\text { Aug } \\
2014\end{array}$ & $3.02 \%$ & $12.73 \%$ & $66.27 \%$ & $17.60 \%$ & $0.38 \%$ \\
\hline
\end{tabular}

Table 3. the percentage of the area of each of the classes of surface temperature in Tehran metropolis.

In order to Evaluation of temporal distribution changes of the LST of tehran, was investigated the trend of temporal changes for every classes, separately.

According to the table 3 , the achieved results show (between 1999 to 2014) the verey low temperature regions and the middle temperature regions were reduced by the rate of $0.54 \%$ and $5.67 \%$ respectively. On the other hand, the high temperature and the very high temperature regions were increased by $3.68 \%$ and $0.38 \%$ respectively. These results indicate an incremental procedure on the distribution of the hot regions in Tehran in this period. In the following in order to investigate the temporal change of heat island intensity of Tehran metropolis, between the years 1999 to 2014, the Urban heat island ratio index (URI) was applied. The index (URI) based on the equation (9) for 1999 is equal 0.11 and for 2014 is estimated 0.14 . The greater the index, the more intense the UHI was. Eventually, Considering URI between 1999 and 2014, an increasing about 0.03 was shown.

\section{CONCLUSIONS}

in this paper, a time series was generated by Landsat8 and Landsat7 satellite images to analysis the changes in the spatial and temporal distribution of the Tehran's LST. In this process, The Normalized Difference Vegetation Index (NDVI) threshold method was applied to extract the LST; then the changes in spatial and temporal distribution of LST over the period 1999 to 2014 were evaluated by the statistical analysis. Finally, the achieved results show the very low temperature regions and the middle temperature regions were reduced by the rate of $0.54 \%$ and $5.67 \%$ respectively. On the other hand, the high temperature and the very high temperature regions were increased by $3.68 \%$ and $0.38 \%$ respectively. These results indicate an incremental procedure on the distribution of the hot regions in Tehran in this period. To quantitatively compare urban heat islands (UHI), an index called Urban Heat Island Ratio Index(URI) was calculated. It can reveal the intensity of the UHI within the urban area. The calculation of the index was based on the ratio of UHI area to urban area. The greater the index, the more intense the UHI was. Eventually, Considering URI between 1999 and 2014, an increasing about 0.03 was shown. The reasons responsible for the changes in spatiotemporal characteristics of the LST were the sharp increase in impervious surfaces, increased use of fossil fuels and greening policies.

\section{REFERENCES}

Amiri, K., Weng, Q., alimohamadi, A., alavipanah, K., 2009. Spatial-temporal dynamics of land surface temperature in relation to fractional vegetation cover and land use/cover in the Tabriz urban area Iran. Remote Sensing of Environment, Vol. 113, pp. 2606-2617.

Artis, D.A. and Carnahan, W.H., 1982, Survey of Emissivity Variability in Thermography of Urban Areas, Remote Sensing of Environment, 12: 313-329.

Balling R. C., Brazell., S. W., 1988. High resolution surface temperature patterns in a complex urban terrain. Photogrammetric Engineering and remote sensing, Vol. 54, No. 9, pp. 1289-1293.

Chen, Q., Ren, J., Li, Z., Ni, C., 2009. Urban Heat Island Effect Research in Chengdu City Based on MODIS Data. In Proceedings of 3rd International Conference on Bioinformatics and Biomedical Engineering, Beijing, China,, 1-5.

Dai, X., Guo., Z., Zhang., L., Li. D., 2010. Spatio temporal exploratory analysis of urban surface temperature field in Shanghai, China.Stoch Environ Res Risk Assess, Vol. 24, pp. 247-257.

Gaffin, S. R., Rosenzweig, C., Khanbilvardi, R., Parshall, L., Mahani, S., Glickman, H., Goldberg, R., Blake, R., Slosberg, R. B., Hillel, D., 2008. Variations in New Yourk city urban heat island strength over time and space, Theoretical and Applied Climatology, Vol. 94, pp. 1-11.

Landsat 7 Science Data Users Handbook, 2006, URL: http://ltpwww.gsfc.nasa.gov/IAS/ handbook_toc.html.

Li, J., 2006. Estimating land surface temperature from Landsat5 TM. Remote Sens. Technol. Appl, Vol. 21, pp. 322-326.

Malekpour P., Taleai., M., Rezaei., Y., 2010. Remote sensingbased spatial-temporal analysis of urban land surface temperature related to urban development: a case study of Tehran, $6^{\text {th }}$ International Remote Sensing \& GIS Conference and Exhibition, Putra World Trade Centre, Kuala Lumpur, Malaysia. 
Pongracz, R., Bartholy, J., Dezso, Z., 2006. Remotely sensed thermal information applied to urban climate analysis, Advances in Space Research, Vol. 37, pp. 2191-2196.

Rose, A.L., Devadas., M. D., 2009. Analysis of land surface temperature and land use/land cover types using remote sensing imagary a case inchennal city, india. The seventh International Conference on Urban Climate, Yokohama, Japan.

Sobrino, J.A., Caselles, V. and Becker, F., 1990, Significance of the Remotely Sensed Thermal Infrared Measurements Obtained Over a Citrus Orchard, ISPRS Photogrammetric Engineering and Remote Sensing, 44: 343-354.

Sobrino, J. A., Jimenez, M., Paolinib, C. J., 2004, Land surface temperature retrieval from LANDSAT TM5, Remote Sensing of Environment, Vol. 90, 434-440.

Sobrino, J.A., Raissouni, N., and Li, Z. L., 2001, A Comparative Study of Land Surface Cmissivity Retrieval from NOAA Data, Remote Sensing of Environment, 75: 255- 267.

Weng, Q., 2001. A remote sensing-GIS evaluation of urban expansion and its impact on surface temperature in the Zhujiang Delta, China.International Journal of Remote Sensing, Vol. 22, No. 10, pp. 1999-2014.

Weng, Q., Yang, S., 2004. Managing the adverse thermal effects of urban development in a densely populated Chinese city, Journal of Environmental Managemnt, Vol. 70, pp. 145156.

Xiao, J., Moody, A., 2005. A Comparison of Methods for Estimating Fractional Green Vegetation Cover within a Desert to Upland transition Zone in Central New Mexico, Remote Sensing of Environment, 237-250.

Xu H., Chen., B., 2004. Remote sensing of the urban heat island and its changes in Xiamen City of SE China. Journal of Environmental Sciences, Vol. 16, pp. 276-281.

Xu H., Chen., Y., Dan., S., Qiu. W., 2011. Spatial and temporal analysis of urban heat island effect in Chengdu city by remote sensing. Geoinformatics, 19th international conference on, shanghai, pp. 1-5.

Xu H., Ding., F., Wen. X., 2009. Urban expansion and Heat Island Dynamics in the Quanzhou Region. China.IEEE journal of selected topics in applied earth observations and remote sensing, Vol. 2, No. 2, pp. 74- 79. 